\title{
Globe
}

Revue internationale d'études québécoises

\section{Parutions récentes en études québécoises}

\section{Michel Lacroix}

Volume 7, numéro 2, 2004

URI : https://id.erudit.org/iderudit/1000874ar

DOI : https://doi.org/10.7202/1000874ar

Aller au sommaire du numéro

Éditeur(s)

Globe, Revue internationale d'études québécoises

ISSN

1481-5869 (imprimé)

1923-8231 (numérique)

Découvrir la revue

Citer ce document

Lacroix, M. (2004). Parutions récentes en études québécoises. Globe, 7(2),

215-221. https://doi.org/10.7202/1000874ar d'utilisation que vous pouvez consulter en ligne.

https://apropos.erudit.org/fr/usagers/politique-dutilisation/ 


\section{Parutions récentes en études québécoises}

$1^{\text {er }}$ avril au 31 décembre 2004

Nos lecteurs sont invités à nous faire part des parutions récentes en études québécoises publiées à l'étranger.

Henry Aubin, Who's Afraid of Demergers? The Straight Goods on Quebec's Megacities, Montréal, Véhicule Press, 2004, ISBN 1-55065-185-4

Tony Babinski et Kristian Manchester, 20 ans sous le soleil, Montréal, Hurtubise HMH, 2004, ISBN 2-89428-738-0 [sur le Cirque du Soleil]

Josée Bélisle [avec la collaboration de Sam Abramovitch], La magie des signes. EEuvres sur papier de la Collection Borduas du Musée d'art contemporain de Montréal, Montréal, Musée d'art contemporain de Montréal, 2004, ISBN 2-551-22533-7

Josée Bélisle, Part de vie, part de jeu. Une incursion critique dans l'œevre graphique et sculpturale de Michel Goulet, Montréal, Musée d'art contemporain de Montréal, 2004, ISBN 2-551-22564-7

Frédérique Bernier, Les essais de Jacques Brault. Seuils et effacements, Saint-Laurent, Fides, coll. " Nouvelles études québécoises ", 2004, ISBN 27621-2589-8

Hélène-Andrée Bizier et Robert-Lionel Séguin, Le menu quotidien en Nouvelle-France, Montréal, Art global, 2004, ISBN 2-920718-92-4

Michel Lacroix [éd.], - Parutions récentes en études québécoises *, Globe. Revue internationale d'études québécoises, vol. 7, n², 2004. 


\section{REVUE INTERNATIONALE D'ÉTUDES QUÉBÉCOISES}

Alix Boucard, La communauté baitienne de Montréal, Montréal, Fondation littéraire Fleur de Lys, 2004, ISBN 0-9736192-1-X

Gérard Bouchard, La pensée impuissante. Échecs et mythes nationaux canadiens-français, 1850-1960, Montréal, Boréal, 2004, ISBN 2-76460345-2

Stéphane Castonguay et Camille Limoges, François Blanchet. L'étudiant et le savant, Montréal, VLB, coll. "Études québécoises ", 2004, ISBN 289005-884-0 [sur un politicien québécois du $\mathrm{xIX}^{e}$ siècle]

Pierre Châtillon, Le mal-né, Sainte-Foy, Presses de l'Université du Québec, 2004, ISBN 2-7605-1300-9 [sur la souffrance dans la littérature québécoise]

Luc Dancause [et al.], La vie démocratique montréalaise. Une revue critique des grands dossiers, Montréal, Société de développement communautaire de Montréal, 2004, ISBN 0-9688633-5-3

Françoise David, Bien commun recherché. Pour un Québec citoyen, Montréal, Éditions Écosociété, 2004, ISBN 2-923165-05-5

Esther Delisle et Pierre K. Malouf, Le quatuor d'Asbestos. Autour de la grève de l'amiante, Montréal, Éditions Varia, coll. "Histoire et société ", 2004, ISBN 2-922245-96-9

Mourad Djebabla-Brun, Se souvenir de la Grande Guerre. La mémoire plurielle de 14-18 au Québec, Montréal, VLB, coll. "Études québécoises ", 2004, ISBN 2-89005-883-2

Martin Dubois [éd.], Recyclage architectural à Québec. 60 réalisations créatives, Sainte-Foy, Publications du Québec, 2004, ISBN 2-551-19666-3

Guy Durand, Le Québec et la laïctté. Avancées et dêrives, Montréal, Éditions Varia, coll. "Sur le vif ", 2004, ISBN 2-89606-010-3

Michelle Duval [et al.], Les organismes communautaires au Québec. Pratiques et enjeux, Montréal, G. Morin, 2004, ISBN 2-89105-900-X 


\section{PARUTIONS RÉCENTES EN ÉTUDES QUÉBÉCOISES}

École de technologie supérieure, Trente ans de génie et d'audace. Éléments pour une bistoire de l'ETS, Sainte-Foy, Presses de l'Université du Québec, 2004, ISBN 2-7605-1331-9

Jean Faucher, Albert Millaire. Entretiens, Montréal, Québec Amérique, 2004, ISBN 2-7644-0360-7

Jean-Louis Fleury, Les porteurs de lumières. L'bistoire de la distribution de l'électricité au Québec, Sainte-Foy, Éditions MultiMondes, 2004, ISBN 289544-058-1

Richard Foisy [éd.], Les Casoars. En souvenir des dîners du Casoar-Club, Montréal, Éditions Varia, coll. "Mémoires et souvenirs ", 2004, ISBN 2922245-77-2 [sur un regroupement d'intellectuels québécois du xxe siècle]

Alain-Gustave Gagnon et Geneviève Nootens, Désenclaver la démocratie. Des buguenots à la paix des braves, Montréal, Québec Amérique, coll. "Débats ^, 2004, ISBN 2-7644-0362-3

Maurizio Gatti [éd.], Littérature amérindienne du Québec. Écrits de langue française, Montréal, Hurtubise $\mathrm{HMH}$, coll. "Littérature ", 2004, ISBN 2-89428-756-9

Andrée Gendreau [éd.], La réserve muséale de la Capitale nationale. Pour une conservation moderne et sécuritaire, Sainte-Foy, Éditions MultiMondes, coll. "Muséo n, 2004, ISBN 2-89544-061-1

Jean-Louis Jobin [éd.], Plume traversière, L'Ancienne-Lorette, Jean-Louis Jobin, 2004, ISBN 2-9801831-5-6 [sur la prose québécoise]

Jean-Pierre Kesteman et al., Histoire du syndicalisme agricole au Québec, Montréal, Boréal, 2004, ISBN 2-7646-0347-9

George A. Klinck, Louis Fréchette. Mémoires intimes, [préface de Michel Dassonvillel, Saint-Laurent, Bibliothèque québécoise, 2004, ISBN 289406-243-5

Micheline Labelle, François Rocher et Ann-Marie Field [éd.], Contestation transnationale, diversité et citoyenneté dans l'espace québécois, SainteFoy, Presses de l'Université du Québec, 2004, ISBN 2-7605-1317-3 
André Lachance, Vivre, aimer et mourir en Nouvelle-France et Juger et punir en Nouvelle-France. La vie quotidienne aux XVIF et XVII siècles, Outremont, Libre expression, coll. "Zénith ", 2004, ISBN 2-7648-0163-7

Carl Lacharité et Gilles Pronovost [éd.], Comprendre la famille. Actes du 7e Symposium québécois de recberche sur la famille, Sainte-Foy, Presses de l'Université du Québec, 2004, ISBN 2-7605-1296-7

Laurier Lacroix, Ozias Leduc à la Catbédrale. Parcours-découverte, Joliette, Musée d'art de Joliette, 2004, ISBN 2-921801-30-2

Marie-Josée Lacroix [éd.], $10+1$ designers : Commerce Design Montréal, Montréal, Éditions Infopresse, 2004, ISBN 2-9802046-3-3

Dominique Lafon [éd.], Approcbes de la biograpbie au Québec, SaintLaurent, Fides, coll. "Archives des lettres canadiennes ", 2004, ISBN 2 7621-2591-X

Marcel Lajeunesse, Lecture publique et culture au Québec. XIX et $X X^{e}$ siècles, Sainte-Foy, Presses de l'Université du Québec, coll. "Gestion de l'information ", 2004, ISBN 2-7605-1298-3

André Lamontagne, Les voix sous les mots. Intertextualité du roman québécois contemporain, Saint-Laurent, Fides, coll. "Nouvelles études québécoises ", 2004, ISBN 2-7621-2602-9

Karim Larose, La langue de papier. Spéculations linguistiques au Québec, 1957-1977, Montréal, Presses de l'Université de Montréal, coll. " Espace littéraire ", 2004, ISBN 2-7606-1953-2

Andrée Lemieux, François-Marc Gagnon et Laurier Lacroix, Regards sur l'art québécois. La collection d'oeuvres d'art de l'Université de Montréal, Montréal, Presses de l'Université de Montréal, 2004, ISBN 2-7606-1971 0

Jocelyn Létourneau, Le Québec, les Québécois. Un parcours bistorique, Saint-Laurent, Fides, coll. "Images de sociétés", 2004, ISBN 2-76212585-5 
André Lortie [avec la collaboration de Marcel Fournier et al.], Les années 60. Montréal voit grand, Vancouver, Douglas \& McIntyre, 2004, ISBN $1-55365-026-3$

Réal Lussier [avec la collaboration de Michaël La Chance], Laurent Pilon. Le cri muet de la matière, Montréal, Musée d'art contemporain de Montréal, 2004, ISBN 2-551-22542-6

Marie-Victorin, Mon miroir. Journal, 1903-1920, Gilles Beaudet et Lucie Jasmin [éd.], Saint-Laurent, Fides, 2004, ISBN 2-7621-2569-3

Nancy Marrelli, L'Université Concordia à travers l'bistorique de ses bâtiments, Montréal, Concordia University Archives, 2004, ISBN 0-88947$426-5$

Nancy Marrelli, Stepping Out. The Golden Age of Montreal Night Clubs, Montréal, Véhicule Press, 2004, ISBN 1-55065-193-5.

Guylaine Massoutre, L'atelier du danseur, Saint-Laurent, Fides, coll. " Métissage ", 2004, ISBN 2-7621-2576-6 [sur la danse moderne québécoise]

Marie-Josée Michaud, Claude Léveillée. En mosaique, Tome 1 1932-1961, Montréal, Art global, 2004, ISBN 2-920718-90-8

Michel Moreault, Édith-Anne Pageot et François-Marc Gagnon, Max Stern, marchand et mécène à Montréal, Montréal, Musée des beaux-arts de Montréal, 2004, ISBN 2-89192-276-X

Rodolphe Morissette, La presse et les tribunaux. Un mariage de raison, Montréal, Wilson \& Lafleur, 2004, ISBN 2-89127-649-3 [chroniques judiciaires québécoises]

Pierre Nepveu, Lectures des lieux, Montréal, Boréal, coll. "Papiers collés n, 2004, ISBN 2-7646-0294-4

France Ouellet [sous la supervision de Michel Biron], Répertoire numérique du fonds Gaston-Miron, Montréal, Bibliothèque nationale du Québec, 2004, ISBN 2-551-22544-2 
Robert L. Rivest et Guy Poirier lavec la collaboration de Hélène Fréchette], Les nouvelles normes de protection en cas de barcèlement psychologique au travail. Une approche moderne, Cowansville, Éditions Y. Blais, 2004, ISBN 2-89451-762-9

Jacques Rouillard, Le syndicalisme québécois. Deux siècles d'bistoire, Montréal, Boréal, 2004, ISBN 2-7646-0307-X

Alain Roy, Gabrielle Roy. L'idylle et le désir fantôme, Montréal, Boréal, coll. "Cahiers Gabrielle Roy ", 2004, ISBN 2-7646-0256-1

Marc Saint-Hilaire et Richard Marcoux [éd.], Population et urbanisation au Québec et au Canada, $X X^{e}$ et $X X^{e}$ siècles, Québec, CIEQ, coll. "Cheminements ", 2004, ISBN 2-921926-23-7

Anne-Marie Sicotte, Quartiers ouvriers d'autrefois, 1850-1950, SainteFoy, Publications du Québec, coll. "Aux limites de la mémoire ", 2004, ISBN 2-551-19650-7

Marie-Blanche Tahon, Vers l'indifférence des sexes : mariage homosexuel et filiation, Montréal, Boréal, 2004, ISBN 2-7646-0348-7 [droit des homosexuels au Québec]

Ismène Toussaint, Les chemins retrouvés de Gabrielle Roy. Témoins d'occasion au Québec, [préface de Réginald Hamell, Outremont, Stanké, 2004, ISBN 2-7604-0966-X

Gilles Tremblay, Félix Fonséca et Richard Lapointe-Goupil, Portrait des besoins des bommes québécois en matière de santé et de services sociaux, Sainte-Foy, CRI-VIFF, coll. "Études et analyses ", 2004, ISBN 2-921768$52-6$

Micheline Tremblay et Guy Gaudreau [éd.], Conversation poétique. Correspondance littéraire entre Harry Bernard et Alfred DesRochers, Ottawa, Éditions David, coll. "Voix retrouvée ", 2004, ISBN 2-89597-032-7

Sébastien Vincent, Laissés dans l'ombre. Quatorze Québécois racontent leur participation volontaire à la Seconde Guerre mondiale, Montréal, VLB, coll. "Études québécoises ", 2004, ISBN 2-89005-879-4 


\section{PARUTIONS RÉCENTES EN ÉTUDES QUÉBÉCOISES}

\section{Traductions}

Roch Carrier, The Flying Canoe, [traduction de Chasse-galerie par Sheila Fischman], Toronto, Tundra Books, 2004, ISBN 0-88776-636-6

Michèle Febvre [avec la collaboration de Laurier Lacroix et al.], JeanPierre Perreault. Alternate Visions, [traduction de Jean-Pierre Perreault. Regard pluriel par Steven Sachs], Montréal, Blue Dawn Press, 2004, ISBN 0-9735284-0-0

Raymonde Litalien and Denis Vaugeois [éd.], Champlain. The Birth of French America, [traduction de Champlain. La naissance de l'Amérique française par Käthe Roth], Montréal, McGill-Queen's University Press, 2004, ISBN 0-7735-2850-4

Pierre Nepveu, Mirabel, Itraduction de Lignes aériennes par Judith Cowan], Montréal, Signal Edition, 2004, ISBN 1-55065-191-9

Michel Tremblay, Some Night my Prince Will Come, Itraduction de La nuit des princes charmants par Sheila Fischman, Vancouver, Talonbooks, 2004, ISBN 0-88922-510-9 